tumour response was nine months (range 6-26 months). The median duration of antitumour response is rarely reported, but, in one large co-operative group study of the antimetabolites, using 5-fluorouracil and methotrexate as single agents, the median duration of response was eight to 10 weeks (Eastern Co-operative Group in Solid Tumour Chemotherapy, 1967). Furthermore, the survival of the responders was only slightly better after six months of follow-up than the nonresponders with only $20 \%$ surviving at one year.

In most trials of combination chemotherapy the multiple agents were administered continuously (Cooper, 1969; Ansfield, et al., 1971). We thought that this approach, though effective, would result in a considerable reduction in dose, and to overcome this we used a cyclic or intermittent regimen. Vincristine was included in the earlier trials referred to above, but we did not give it because of possible severe neurotoxicity with prolonged administration and its low single-drug response rate.

Greenspan (1966) reported a $60 \%$ response rate with a combination of thiotepa and methotrexate without vincristine and $30 \%$ of his patients survived one year. Human breast cancer is a heterogenous disease, and it seems that our regimen is more effective in cases which metastasize rapidly. It uses rather high intravenous doses of the antimetabolites 5-fluorouracil and methotrexate. Tumours with a relatively high fraction of cells in the active cell cycle proliferation may reasonably be assumed to be likely to respond to this type of regimen.

The adjuvant administration of cytotoxic drugs after primary surgery with or without radiation therapy has shown some advantage in patients with a risk of developing metastatic disease (Nissen-Meyer et al., 1971). The rationale for this approach is that drug therapy might be more effective when the tumour cell mass in clinically undetectable. Our results in patients previously untreated with cytotoxic drugs suggest that combined chemotherapy is effective in reducing even large amounts of tumour with tolerable toxicity. If the subsequent pattern of metastatic disease can be predicted from clinical investigation of the biological characteristics of the primary tumour then our form of intensive combined therapy may be more effective for selected patients at risk of developing disseminated disease.

Requests for reprints should be sent to Dr. George P. Canellos.

\section{References}

Ansfield, F. J., Ramirez, G., Korbitz, B. C., and Davis, H. L. (1961). Cancer Chemotherapy Reports, 55, 183.

Ansfield, F. J., Ramirez, G., Mackman, S., Bryan, G. T., and Curreri, A. R. (1969). Cancer Research, 29, 1062.

Cooper, R. G. (1969). Proceedings of the American Association for Cancer Research, 10, 15 .

DeVita, V. T., and Schein, P. S. (1973). New England fournal of Medicine, 285, 998.

Eastern Co-operative Group in Solid Tumour Chemotherapy (1967). Fournal of the American Medical Association, 200, 770.

Fracchia, A. A., Farrow, J. H., Adam, Y. G., Monroy, J., and Knapper, W. H. (1970). Cancer, 26, 642.

Greenspan, E. Z. (1966). Fournal of the Mount Sinai Hospital, 33, 1

Nemoto, T., and Dao, T. L. (1971). New York State Fournal of Medicine, 71, 554 .'

Nissen-Meyer, R., Kjellgren, K., and Mansson, B. (1971). Cancer Chemo-

therapy Reports, 55, 561. Reports, 50, 271.

\title{
Reversible Encephalopathy Possibly Associated with Bismuth Subgallate Ingestion
}

\author{
RICHARD BURNS, D. W. THOMAS, V. J. BARRON
}

British Medical fournal, 1974, 1, 220-223

\section{Summary}

Four patients who had undergone abdominoperineal resection for carcinoma of the colon and who had been taking oral bismuth subgallate developed a stereotyped recurrent and reversible neurological syndrome. This was characterized by confusion, tremulousness, clumsiness, myoclonic jerks, and an inability to walk. All patients were extensively investigated and no cause could be found, but symptoms regressed when the intake of bismuth was stopped. Postmortem examination in one patient failed to show any appreciable abnormality apart from a loss of Purkinje cells in the cerebellum. In the other three patients amino-acid chromatography performed on urine showed the presence of an abnormal unidentified constituent. It is thought that these four patients developed an encephalopathy associated with their bismuth subgallate ingestion.

\footnotetext{
Department of Neurology, Royal Adelaide Hospital, and Institute of Medical and Veterinary Science, Adelaide, South Australia 5000 RICHARD BURNS, F.R.A.C.P., M.R.C.P., Visiting Neurologist

D. W. THOMAS, B.MED.SC., F.R.A.C.P., Assistant Director, Clinical Chemistry

V. J. BARRON, F.R.A.C.P., Physician
}

\section{Introduction}

Recurrent reversible confusional states lasting for several weeks are not common, especially in people who are apparently otherwise in good health. When caused by spontaneous hypoglycaemia the confusion is of shorter duration. Metabolic disturbances such as hyponatraemia or acute intermittent porphyria can be readily detected by appropriate biochemical tests, while the confusional states associated with failure of vital organs such as the heart, lungs, liver, and kidney are usually clinically obvious. There are other conditions in which an intermittent confusional state may be seen such as drug or alcohol intoxication, and sometimes even structural lesions of the brain such as an intermittent hydrocephalus. When there is a history of previous surgery for cancer then cerebral secondary deposits and the rare disorders of progressive multifocal leucoencephalopathy (Cavanagh et al., 1959) and limbic encephalitis (Corsellis et al., 1968) should also be considered, though these conditions usually have a progressive course.

We report on four patients who developed a very similar recurrent and reversible neurological syndrome consisting essentially of confusion, tremulousness, clumsiness, myoclonic jerks, and an inability to walk. In none of the patients were we able to identify any definable metabolic or structural disorder which could have been responsible.

\section{Case 1}

A 43-year-old farmer had an abdominoperineal resection for a carcinoma 
of the colon in 1966, after which he took charcoal by mouth together with a third of a teaspoon of bismuth subgallate three times a day. Two years later he had a poorly-documented illness, in which he became drowsy for about a week, and after which he was unable to work on his farm because of tremulousness, clumsiness, and a poor memory. He was unable to do his accounts or taxation returns, though previously able to do so. He lost all libido. His symptoms seemed to fluctuate to some extent, but in 1970 his tremulousness and confusion became such that he was admitted to hospital. At that time he was an alert, but rather tremulous man who was correctly orientated, but he performed memory tests very poorly. He showed numerous myoclonic jerking movements, mainly involving the hands, he was unable to write, and his gait was unsteady. No lateralizing neurological signs were found, and the rest of the neurological examination, as well as the general examination, showed nothing abnormal.

On extensive investigation the blood film, serum electrolytes, urinary porphyrins, thyroid function, liver function, and radiographs of his skull and chest were found to be normal. The electroencephalogram showed photo myoclonus at $10-12 \mathrm{~Hz}$ but was otherwise normal. The spinal fluid was under normal pressure with a protein concentration of $64 \mathrm{mg} / 100 \mathrm{ml}$ (normal $10-40 \mathrm{mg} / 100 \mathrm{ml}$ ), with no excess globulin, and no cells were seen. A brain scan was of normal appearance, as was an air encephalogram. His condition improved after several weeks and he was discharged. He was readmitted on numerous occasions over the next few months because of recurrence of his confusion and tremulousness. On each admission it was noted that he had confusion of varying severity, persistent memory deficit, myoclonic jerkings of the arms and sometimes of the legs, with tremulousness, and he had great difficulty in walking. At no stage were any focal neurological signs observed. Many of the investigations were repeated, but no consistent abnormality was found; though on one admission there was a transient rise of serum urea nitrogen and sodium concentrations which soon reverted to normal with treatment of an associated dehydration. So far as we know he did not receive bismuth subgallate while in hospital, but took it when at home. During his last admission he became delirious, had several grand mal epileptic attacks, and finally died. At necropsy, terminal pulmonary oedema was found. His brain and spinal cord were extensively examined. There was no evidence of metastases in the nervous system or elsewhere. There was no evidence of inflammation, demyelination, or inclusion bodies in the brain, and the only abnormal finding was a paucity of Purkinje cells in the cerebellum.

\section{Case 2}

A 55-year-old businessman had an abdominoperineal resection for carcinoma of the colon in June 1971. He was subsequently given bismuth subgallate by mouth, and was told to take a third of a teaspoon twice a day, but he probably took one level teaspoon twice a day. Ten months after his operation he became irritable and antisocial, and had lapses of memory. His gait became ataxic and he was generally clumsy. One grand mal epileptic attack occurred. He was admitted to hospital where he was noted to be confused and demented, and unable to understand or co-operate. There was tremulous shaking of both legs, and he was unable to walk. No focal neurological signs were found.

On investigation the blood film, serum vitamin $B_{12}$ and folic acid, thyroid function, and radiographs of skull and chest were normal, and a brain scan was of normal appearance. His serum electrolytes were normal, except for a marginal increase of serum urea nitrogen concentration. His venereal disease research laboratory test was non-reactive. His spinal fluid protein concentration was $35 \mathrm{mg} / 100 \mathrm{ml}$, and no cells were found. Urinary amino-acid chromatography showed normal excretions of amino-acids, but an unusual faint spot with atypical characteristics was observed. This urinary constituent has not yet been identified.

After three weeks his condition had improved greatly and it was noted then that he performed his intellectual tests well and that the tremulousness had disappeared. He was discharged from hospital, but two months later he was readmitted with a recurrence of his confusion and ataxia. Similar findings were observed on examination as at the previous admission, and he was again investigated extensively without any abnormal findings, except that air encephalography showed mild generalized cerebral and cerebellar atrophy. After three weeks he had again recovered and was discharged. However, within nine days he was readmitted in a confused and ataxic state, and on this occasion bismuth subgallate was continued while in hospital in a dose of one teaspoon three times a day. His condition did not improve so he was transferred to a nursing home for terminal care. Within three weeks he had recovered and was sent home. It is not known if he received bismuth subgallate while there. In November 1972 his bismuth subgallate was finally stopped, and 10 months later there had been no further episodes of confusion or ataxia. He is now playing bowls and driving his car, and his intellect and behaviour are normal.

\section{Case 3}

A 52-year-old housewife underwent an abdominoperineal resection in August 1971 for carcinoma of the colon. She was then advised to take a third of a teaspoon of bismuth subgallate by mouth twice daily. Six months after the operation she became shaky and tremulous, being unable to hold a cup of tea. She recovered spontaneoulsy in 10 days. In May 1972 she again became unsteady and confused, with disorientation in time and place, and was inattentive and hallucinated. Her gait disturbance was so great that she had to be carried to the shower. Occasionally she was incontinent of urine. There seemed to be a wide fluctuation in her mood and degree of alertness, but after two weeks she recovered well. In July 1972 she again became confused and agitated, with jerky involuntary movements and an inability to walk. As with her previous two attacks this episode seemed to coincide with her menstrual period. Examination showed disorientation in time and place with an inability to perform routine intellectual tests. She was having visual and auditory hallucinations, and exhibited tremulousness and frequent myoclonic jerks, particularly involving the arms. She was unable to sit or stand, and attempts at walking were associated with a gross increase in her tremulousness and agitation. No focal neurological signs were found.

On investigation the blood film, serum vitamin $B_{12}$, folic acid, serum electrolytes (including sodium, magnesium, and calcium) serum glucose, thyroid function tests, radiographs of her skull and chest, brain scan, and an electroencephalogram were all found to be normal. No significant amounts of lead, arsenic, or mercury were found in the urine. Her spinal fluid protein concentration was 44 $\mathrm{mg} / 100 \mathrm{ml}$ (normal $10-40 \mathrm{mg} / 100 \mathrm{ml}$ ) with a normal percentage of gammaglobulin, and no cells were found. Amino-acid chromatography showed slightly increased excretions of arginine and alanine in her urine with an extra spot which could not be identified.

She recovered within a few weeks and was discharged from hospital. Over the next few months she had further episodes of a minor nature consisting of shaking and loss of balance. In June 1973 she had a further episode of confusion and tremulousness again related to the onset of her menses and to the ingestion of bismuth subgallate, which she had stopped several months before. This was one of the worst attacks, but after six weeks she had almost fully recovered. She had ceased to take bismuth subgallate shortly after the attack began. Urinary amino-acid chromatography was repeated during this last attack, with similar findings to those described above.

\section{Case 4}

A 70-year-old retired clerk had an abdominoperineal resection for carcinoma of the rectum in 1965 . He had been taking charcoal by mouth together with one-third of a teaspoon of bismuth subgallate regularly since the operation. He drank alcohol but not to excess and his diet was good. Six years later he had an episode of confusion and loss of memory, together with jerking spasms of the arms and difficulty in walking which lasted for about three weeks. He was investigated in a country hospital and his symptoms cleared without any cause being found. He was allegedly constipated before the onset of this illness. In June 1973 he again developed difficulty in walking, poor concentration, and tremulousness over a period of several days. For two weeks before this his colostomy had been working less often. He had continued to take his bismuth subgallate. Examination at that time showed confusion and disorientation. Limb movements were clumsy and ataxic and occasional myoclonic jerking movements of the arms and to a less extent of the legs were seen. He was unable to walk or even stand unsupported. When attempts were made to get him to walk he became very tremulous, clinging tightly to the nearest object, and he seemed to have no idea where to put his feet. No focal neurological signs were found and general examination showed nothing abnormal.

On investigation the blood film, serum electrolytes (including serum magnesium, serum vitamin $B_{12}$, and folic acid) liver function tests, red cell transketolase, and an electrocardiogram were all normal. Radiographs of his skull, an electroencephalogram, and a brain scan were also of normal appearance. Radiographs of his chest showed old, calcified tuberculous lesions, but there was no evidence of metastases. 
Routine serological tests for syphilis were non-reactive. The spinal fluid was under normal pressure and contained a protein concentration of $50 \mathrm{mg} / 100 \mathrm{ml}$ (normal $10-40 \mathrm{mg} / 100 \mathrm{ml}$ ) with no excess of globulin, and no cells were seen. Urinary amino-acid chromatography showed normal excretion of amino-acids, but an unusual faint spot with atypical characteristics was observed. This urinary constituent has not yet been identified.

His bismuth subgallate was withdrawn, and over a period of seven days his condition improved remarkably to the extent that he was able to walk, his involuntary movements almost ceased, and he was able to think clearly enough to do crossword puzzles. While he was still in hospital and under careful observation it was decided to reintroduce bismuth subgallate together with codeine to constipate his motions. Over the next 10 days he became tremulous and ataxic and he claimed that he was unable to think clearly. While his neurological condition was not florid it was decided to stop the bismuth subgallate, and within three days his condition had again returned to normal.

\section{Discussion}

We believe that these four patients who all showed a strikingly similar and reversible episodic neurological syndrome were suffering from the same disorder. We have been unable to find a description in the literature of a similar condition.

The onset of their neurological symptoms was usually subacute, with mild confusion and difficulty with concentration for several days or weeks. However, in case 1 mild intellectual impairment had been present for a year or more. The confusional state itself was non-specific but was usually associated with tremulousness and agitation. The severity of these mental symptoms varied from time to time and was not necessarily the same with each exacerbation. Hallucinations were unpleasant and usually visual or auditory. Myoclonic jerking movements were seen in all patients, being especially prevalent in the arms but also seen in the legs. Epileptic seizures occurred in two patients, and were non-focal grand mal attacks. One of the most striking and characteristic features was the gait disturbance. Though no weakness, ataxia, or sensory loss could be observed when the patients were tested in bed, all had difficulty walking at some stage with frequent falling and often they were unable to walk for several days. The gait disability was difficult to categorize, but it seemed to be a combination of ataxia and apraxia. The symptoms and signs were strikingly similar in each of the four patients. There were at least two, and sometimes many more, relapses, which usually lasted for one to two weeks. When recovery did occur it seemed to be complete. All patients were extensively investigated and no biochemical, infective, toxic, or metabolic cause could be found. Case 2 had radiological evidence of mild cerebral and cerebellar atrophy, while the same patient had transient increases of serum sodium and urea nitrogen concentrations which were thought to be due to dehydration. Case 1 died during an acute episode of confusion, but the necropsy findings were normal except for some loss of Purkinje cells in the cerebellum.

In one patient (case 3 ) increased urinary excretions of arginine and alanine were seen. Amino-acid chromatography also showed the presence of an additional ninhydrin-positive spot with similar retention characteristics in cases 2,3 , and 4 . Amino-acid chromatography or urine from other patients with colostomies and who had been ingesting bismuth subgallate showed similar spots. No spot was seen in chromatograms of urine from patients with colostomies who had never ingested bismuth subgallate. The identification and significance of this urinary constituent is currently being investigated and will be the subject of a separate report.

The clinical picture was not that of limbic encephalitis or progressive multifocal leucoencephalopathy which have been described in patients as a remote effect of carcinoma. Three patients drank little or no alcohol while the fourth drank a moderate amount, but his dietary habits were excellent. Though there were some similarities between this syndrome and delirium tremens associated with alcohol withdrawal, this did not seem to be the diagnosis in any of the four patients.
Apart from their clinical signs other similarities were apparent. They had all undergone abdominoperineal resection with a colostomy and all had been taking bismuth subgallate by mouth to reduce the odour and flatulence and to improve the consistency of their motions. While there is not a clear history of excessive ingestion of this substance immediately before the onset of the neurological symptoms, we believe that bismuth subgallate may well be the toxic agent responsible. Again, though it has not been possible to obtain an accurate chronological drug history, it would seem that in all patients bismuth subgallate was stopped while they were in hospital, resulting in clinical improvement. When they returned home it was recommenced, resulting in an exacerbation or relapse of their condition. We have not, of course, explained why some patients are able to take bismuth subgallate for some months or even years without apparent ill effect. In case 1 the exacerbations seemed to occur when the patient was at home where he regularly took the bismuth subgallate, but when in hospital, where it was inadvertently stopped, he recovered, except in his last attack when he died. In case 2 the patient had frequent bouts of confusion, but since he stopped the bismuth subgallate no further neurological episodes had occurred at the time of writing. On the one occasion the bismuth subgallate was not stopped in hospital his condition did not improve. The patient in case 3 remained well for several months when the bismuth subgallate was stopped, but she had a further severe episode when it was restarted. In case 4 the patient recovered from his neurological illness when the bismuth subgallate was withdrawn, but he had a relapse when it was restarted while under careful observation in hospital, only to recover rapidly when it was again withdrawn.

This condition has not been described before, and we think it is important that it be recognized because in Australia, at least, there is a large number of patients with colostomies and many are taking bismuth subgallate. The existence of this syndrome is noteworthy as these patients can easily be thought to have some untreatable condition, such as cerebral secondary deposits, and hence intensive measures to resuscitate them may not be instituted. It is also possible that some patients may be referred to psychiatric units or may even die in small country hospitals because the correct diagnosis has not been made. The exact mechanism of the encephalopathy produced by bismuth subgallate is not yet apparent, nor is the significance of the unusual constituent present in the urine of patients with colostomies who ingest bismuth subgallate. These matters are currently being investigated. It is unlikely that bismuth itself is responsible for the encephalopathy. The neurological syndrome in these patients does not resemble reported effects of bismuth when administered parenterally (Heyman, 1944) or by mouth (Goodman and Gilman, 1965). Little, if any, bismuth is absorbed from the gastrointestinal tract as most is converted to insoluble bismuth sulphide.

\section{ADDENDUM}

Since this report was prepared a funther patient (case 5) has been seen.

A 64-year-old housewife had an abdominoperineal resection for a carcinoma of the colon in November 1972. Subsequently she took a level teaspoon of bismuth subgallate twice a day. About two months after the operation her husband noticed that she was becoming forgetful and that her concentration was poor. Her condition became progressively worse though it did fluctuate. Her writing deteriorated and she dropped things and was no longer able to sew. Ten months after her operation she was unable to dress herself, had difficulty in walking, fell several times, and was periodically incontinent of urine. She was totally dependent on her husband, who by then was doing all the household chores. On examination she was found to be confused and disorientated in time and her intellectual tests were done poorly. She was generally tremulous and clumsy and her gait was wide-based and ataxic. No focal neurological signs were found and no myoclonic jerks were seen. 
Extensive investigations were carried out in hospital including a blood film, serum vitamin $B_{1: 2}$ and folic acid, serum electrolytes, thyroid function, E.E.G., skull radiography, and a brain scan. All these investigations gave normal results. Her spinal fluid protein concentration was $20 \mathrm{mg} / 100 \mathrm{ml}$ (normal $10-40 \mathrm{mg} / 100 \mathrm{ml}$ ). Urinary amino-acid chromatography showed normal excretions of amino-acids, but an unusual faint spot with atypical characteristics was observed. This urinary constituent has not yet been identified.

The bismuth subgaliate was stopped immediately and over a period of two weeks her condition gradually returned to normal. Her mental confusion cleared, she lost her clumsiness and tre- mulousness, and her gait became steady. She is now leading a normal life and according to her husband her intellectual functions have recovered fully.

\section{References}

Cavanagh, J. B., Greenbaum, D., Marshall, A. H. E., and Rubenstein, L. J. (1959). Lancet, 2, 524.

Corsellis, J. A. N., Goldberg, G. J., and Norton, A. R. (1968). Brain, 91, 481. Goodman, L. S., and Gilman, A. (1965). Pharmacological Basis of Therapeutics, 3rd edn. New York, Macmillan.

Heyman, A. (1944). American fournal of Syphilis, Gonorrhea and Venereal Diseases, 28, 721.

\title{
Treatment of Tetanus Neonatorum with Muscle Relaxants and Intermittent Positive-pressure Ventilation
}

\author{
P. M. SMYTHE, M. D. BOWIE, T. J. V. VOSS
}

British Medical fournal, 1974, 1, 223-226

\section{Summary}

Intermittent positive-pressure ventilation and muscle relaxants were first used in Cape Town in 1958 in an attempt to reduce the mortality from tetanus neonatorum, which was then over $90 \%$. Problems of effective ventilation, of tracheostomy, and of infection in the neonate were gradually overcome so that between 1967 and 1972 the mortality in 186 cases was $21 \%$. In a consecutive series of 97 cases the mortality was $10 \%$.

\section{Introduction}

Until preventive measures are widely established neonatal tetanus will remain a problem in many parts of the world, with a mortality in the region of $90 \%$ on conservative treatment. A regimen of treatment with intermittent positivepressure ventilation (I.P.P.V.) and muscle relaxants, which has been evolved after much trial and error, is described because it has stood the test of time and of changes of staff, has greatly reduced the mortality and, it is hoped, will prove helpful in areas where tetanus neonatorum is still a problem.

\section{Patients and Methods}

On admission to hospital all cases received 1-2 $\mathrm{ml}$ paraldehyde intramuscularly or 1-2 mg diazepam (Valium) to help control the spasms and were given oxygen as required. Antitetanic serum 10-20,000 $U$ intravenously and 20,000 $U$ intramuscularly in divided doses was given at four different sites on the outer aspect of the thigh. Intramuscular gammaglobulin 2 $\mathrm{ml}$ helped to control infection, and $1-2 \mathrm{mg}$ vitamin $K_{1}$ was

University of Natal, Durban, Natal, South Africa

P. M. SMYTHE, M.D., F.R.C.P., Professor of Paediatrics and Child Health

University of Cape Town, Cape, South Africa

M. D. BOWIE, F.R.C.P., D.C.H., Senior Lecturer, Department of Paediatrics and Child Health; Principal Paediatrician, Red Cross War Memorial Children's Hospital, Rondebosch, Cape

T. J. V. VOSS, M.B., D.A., Senior Lecturer, Department of Anaesthesia; Principal Anaesthetist, Red Cross War Memorial Children's Hospital, Rondebosch, Cape

given intramuscularly to minimize bleeding at tracheostomy. Intramuscular procaine penicillin $100,000 \mathrm{U}$ and kanamycin $15 \mathrm{mg} / \mathrm{kg} /$ day in two doses were given for 10 days to control the unbilical infection and supply antibiotic cover.

A small percentage of neonates with tetanus survived on a conservative regimen of tube feeding and sedation. These infants had mild spasms which did not materially interfere with breathing or swallowing saliva. Severe spasms, a severe cyanotic episode, or any apnoeic episode were absolute indications for tracheostomy and assisted respiration.

\section{TRACHEOSTOMY}

Tracheostomy is best carried out under general anaesthesia with the use of an endotracheal tube. Local anaesthesia alone increases the risk of the procedure. A high tracheostomy with a longitudinal incision through the second, third, and fourth tracheal rings using a short incision of exposure has virtually abolished the complication of pneumothorax. Excision of any cartilage or a transverse incision of the trachea was found to be undesirable.

A Pilling-Holinger tracheostomy tube $5 \mathrm{~mm}$ in diameter (size 1) and $33 \mathrm{~mm}$ long had a T-piece welded on to the inlet to provide a side attachment to the respirator and an end opening for suctioning (fig. 1). Care was taken to see that the spiggot blocking the opening at the end was firmly fixed and could not blow out. Without any cuff the tube fitted snugly into the lumen of the trachea preventing any appreciable leak

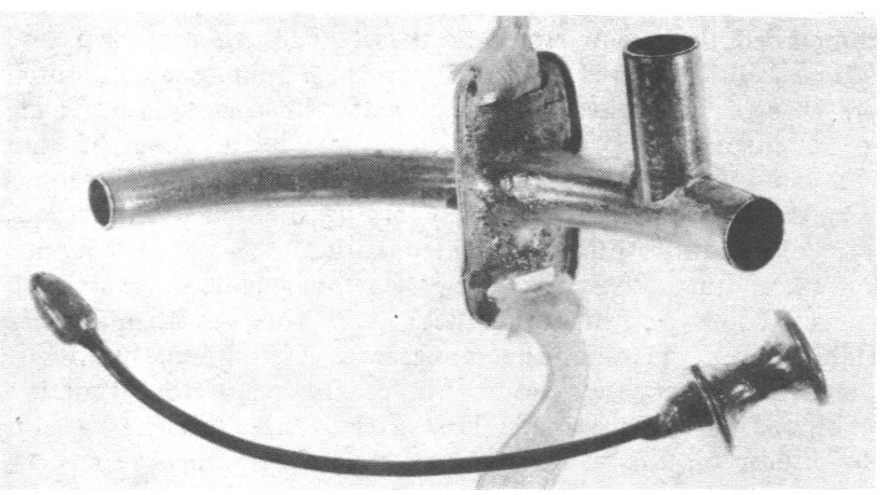

FIG. 1-Pilling-Holinger tracheostomy tube showing T-piece welded on for attachment to ventilator. 